\title{
Caregiving Burden Among Family Members Of People With Mental Illness
}

\author{
Bhandari AR1, Marahatta K², Rana M², Ojha SP4, Regmi MP5
}

1. Clinical Psychologist, Department of Psychiatry, Patan Academy of Health Sciences, Lalitpur 2.Lecturer, Department of Psychiatry, Patan Academy of Health Sciences, Lalitpur 3. Associate Professor, Department of Psychiatry and Mental Health, IOM, TUTH 4. Associate Professor and Head, Department of Psychiatry and Mental Health, IOM, TUTH 5. Retired Professor and Former Head, Central Department of Psychology, Tribhuvan University

E-mail *Corresponding author: anup.simpsn@gmail.com

\section{Abstract}

Background: Presence of a person with mental disorder in family is often associated with some objective and subjective burden on family members, especially those who have a caregiving role. The present study aimed to assess the levels of caregiving burden among family members of people with mental illness.

Method: This is a descriptive cross-sectional study in a sample of 56 family caregivers of people with mental illness. Sample was selected using purposive sampling method and their caregiving experience was assessed by using Burden Assessment Schedule.

Result: Among the 56 caregivers, $48.2 \%$ had moderate level of burden and 32.1\% had severe level of burden. Highly significant difference was observed in the distribution of burden according to level of burden but no significant gender difference was found in the distribution of burden in total and in different domains of BAS. Highly significant burden was found among married and spouse caregivers.

Conclusion: As moderate to severe level of caregiving burden was reported by the family caregivers, it is recommended that family intervention should focus on strengthening coping behaviors and social support system to manage caregiving stress.

Keywords: Family caregiving burden, Mental illness, Burden Assessment Schedule (BAS)

\section{INTRODUCTION}

The presence of a person with mental illness in a family is often associated with objective and subjective burden on family members, especially those who have a caregiving role. The extent of burden depends on several factors like caregiver's age and gender, pre-morbid relationship with patient, patient's problems, coping strategies and perception of patient's illness, emotional and practical support available to the family, coping behavior and socio-cultural and ethnic variables ${ }^{1}$. It is estimated that one in four families has at least one member currently suffering from mental or behavioural disorder ${ }^{2}$. These families are required not only to provide physical and emotional support, but also to bear negative impact of stigma and discrimination present in all parts of the world. While the burden of caring for a family member with a mental or behavioural disorder has not been adequately studied in different socio-cultural context, the available evidences suggest that it is indeed substantial $3,4,5$. The burden on families ranges from economic difficulties to emotional reactions to illness, stress of coping with 
disturbed behaviour, disruption of household routine and restriction of social activities ${ }^{2}$. In 2004, mental disorders accounted for $13 \%$ of global burden of disease ${ }^{6}$. Families who perceived a higher level of caregiver burden are those who lived in a family with poorer functioning, worse health status and less satisfaction of social support ${ }^{7}$.

In the country like Nepal where formal and paid type of caregiving is rarely in practice and psychiatric services are minimal in the community, the major responsibility of caregiving to people with different psychiatric conditions is shouldered by close family members or relatives. Caregiving is a very challenging task where the quality of caregiving determines the well being of individual with disability or illness and also that of caregivers ${ }^{8,9}$. Different aspects of caregivers' life are affected by the task of caregiving and the hidden economic, social and health impacts of caregiving on caregivers ultimately affects treatment outcome and increases the chance of relapse in the case of mental illness. The present study aimed to assess level of caregiving burden among family members of patients with mental illness in the context of Nepal.

\section{MATERIAL AND METHOD}

This is a descriptive and cross sectional study conducted among family caregivers of people with mental illness admitted in Psychiatry Ward of Tribhuvan University Teaching Hospital (TUTH) in a sample $(\mathrm{N}=56)$ fulfilling inclusion criteria using purposive sampling method during the period of 6 months (April 2013 to September 2013). In order to collect primary data, a standardized scale was used to explore the level of family burden of caregiving of the people with mental illness. The scale was in English Language and therefore, translation and back translation was done to develop scale in Nepali language.

Semi-structured pro-forma was used to record the socio-demographic characteristics of both caregivers and their patients. Burden Assessment Schedule (BAS) ${ }^{10}$ was used to collect their caregiving experiences. BAS was developed \& standardized by step wise ethnographic exploration method in India. The inter rater reliability and content validity are high $^{10}$. Criterion validity was established by comparing with Family Burden Interview Schedule ${ }^{11}$ ranging between $0.71-0.82$. There are 40 items rated on a three point scale (1-3): 1mild burden, 2-moderate burden \& 3-severe burden. In this study, the severity of burden was categorized into 4 groups ${ }^{12}$. A score up to 40 on BAS indicate no burden, 41-60 minimal burden, 61-80 moderate burden, 81-100 severe burden and 101-120 very severe burden. There are 9 domains. Increasing scores indicate increasing level of burden. The scale was selected as it can be administered to literate individuals and has similarity in socio-cultural aspects between India and Nepal. Ethical clearance was taken from Institutional Review Board (IRB), Institute of Medicine (IOM), Tribhuvan University. The study variables were analyzed using descriptive and inferential statistics using Statistical Package for Social Sciences (SPSS) version 17 for windows.

\section{RESULT}

\section{Socio-demographic variables}

Among 56 caregivers, the mean age was 39.45 \pm 11.974 (Male: $40.61 \pm 13.295$ and female: $38.29 \pm$ 10.607). Similarly, among caregivers' respective patients, the mean age was $30.62 \pm 13.612$ (male: $31.47 \pm 13.990$ and female: $29.32 \pm 13.22$ ). The $t$ test showed no significant difference in the distribution of age of caregivers $(t=.722, p>.05)$ and of patients $(\mathrm{t}=.654, p>.05)$ by sex.

Similarly, among 56 caregivers, $50 \%$ were male, $42.9 \%$ belonged to $31-45$ years' age group, $75 \%$ were married, $23.2 \%$ had education up to intermediate level, $44.6 \%$ were unemployed, $57.1 \%$ were from urban areas and joint families, $53.6 \%$ were from lower middle socioeconomic status family, and $51.8 \%$ had family history of mental illness. Among 56 patients of these caregivers, $60.7 \%$ were male, $50 \%$ were in the age group of 16-30 years, $46.4 \%$ were unmarried, $32.1 \%$ had secondary level education, $71.4 \%$ were unemployed, $42.9 \%$ were cared by parents, $46.4 \%$ had schizophrenia or psychotic disorders, $51.8 \%$ had total duration of illness more than five years, and $41.1 \%$ had first hospitalization. 
Table 1: Socio-demographic Variables of Caregivers and Burden $(\mathrm{N}=56)$

\begin{tabular}{|c|c|c|c|c|c|c|}
\hline Socio-demographic Variable & $\mathbf{N}$ & Mean & SD & F-ratio & $\mathrm{df}$ & p value \\
\hline Age of Caregiver & & & & & & \\
\hline $18-30$ & 15 & 72.20 & 14.785 & \multirow{5}{*}{-1.054} & \multirow{5}{*}{3} & \multirow{5}{*}{$\begin{array}{l}.132 \\
\text { (NS) }\end{array}$} \\
\hline $31-45$ & 24 & 71.33 & 13.927 & & & \\
\hline $46-60$ & 15 & 80.73 & 10.229 & & & \\
\hline $60-65$ & 2 & 82.00 & 4.243 & & & \\
\hline Total & 56 & 74.46 & 13.497 & & & \\
\hline \multicolumn{7}{|l|}{ Marital Status of Caregiver } \\
\hline Unmarried & 11 & 64.09 & 9.148 & \multirow{4}{*}{5.150} & \multirow{4}{*}{2} & \multirow{4}{*}{$.009 * *$} \\
\hline Married & 42 & 76.50 & 13.549 & & & \\
\hline Widowed & 3 & 84.00 & 3.606 & & & \\
\hline Total & 56 & 74.46 & 13.497 & & & \\
\hline \multicolumn{7}{|l|}{ Education of Caregiver } \\
\hline Literate & 17 & 76.41 & 8.761 & \multirow{7}{*}{2.135} & \multirow{7}{*}{5} & \multirow{7}{*}{$\begin{array}{l}.076 \\
\text { (NS) }\end{array}$} \\
\hline Primary & 3 & 64.00 & 2.000 & & & \\
\hline Secondary & 10 & 72.70 & 10.740 & & & \\
\hline Intermediate & 13 & 68.15 & 15.066 & & & \\
\hline Bachelor & 8 & 80.00 & 16.784 & & & \\
\hline Master & 5 & 85.20 & 17.936 & & & \\
\hline Total & 56 & 74.46 & 13.497 & & & \\
\hline \multicolumn{7}{|l|}{ Occupation of Caregiver } \\
\hline Unemployed & 25 & 72.72 & 13.126 & \multirow{4}{*}{2.982} & \multirow{4}{*}{2} & \multirow{4}{*}{$\begin{array}{l}.059 \\
\text { (NS) }\end{array}$} \\
\hline Employed & 18 & 80.39 & 13.236 & & & \\
\hline Self Employment & 13 & 69.62 & 12.560 & & & \\
\hline Total & 56 & 74.46 & 13.497 & & & \\
\hline \multicolumn{7}{|l|}{ Socioeconomic Status } \\
\hline Upper & 1 & 71.00 & - & \multirow{6}{*}{.227} & \multirow{6}{*}{4} & \multirow{6}{*}{$\begin{array}{l}.922 \\
\text { (NS) }\end{array}$} \\
\hline Upper Middle & 5 & 77.60 & 20.452 & & & \\
\hline Lower Middle & 16 & 73.25 & 14.327 & & & \\
\hline Upper Lower & 30 & 75.27 & 11.962 & & & \\
\hline Lower & 4 & 70.25 & 17.727 & & & \\
\hline Total & 56 & 74.46 & 13.497 & & & \\
\hline \multicolumn{7}{|l|}{ Religion of Caregiver } \\
\hline Hinduism & 45 & 75.29 & 13.48 & \multirow{4}{*}{.731} & & \\
\hline Buddhism & 8 & 69.12 & 14.60 & & & \\
\hline Christianity & 3 & 76.33 & 11.59 & & 2 & .486 \\
\hline Total & 56 & 74.46 & 13.497 & & & (NS) \\
\hline Socio-demographic Variable & $\mathbf{N}$ & Mean & SD & t-test & df & p value \\
\hline Type of Family & & & & & & \\
\hline Nuclear & 24 & 75.75 & 12.432 & & & \\
\hline Joint & 32 & 73.50 & 14.364 & .614 & 54 & .542 \\
\hline Total & 56 & 74.46 & 13.497 & & & (NS) \\
\hline Permanent Residence & & & & & & \\
\hline Rural & 24 & 73.42 & 13.141 & & & \\
\hline Urban & 32 & 75.25 & 13.914 & -.500 & 54 & .619 \\
\hline Total & 56 & 74.46 & 13.497 & & & (NS) \\
\hline $\begin{array}{l}\text { Family History of Mental } \\
\text { Illness }\end{array}$ & & & & & & \\
\hline Yes & 29 & 73.14 & 12.944 & & & \\
\hline No & 27 & 75.89 & 14.173 & -.759 & 54 & .451 \\
\hline Total & 56 & 74.46 & 13.497 & & & (NS) \\
\hline
\end{tabular}

Note: NS $=$ Not significant, ${ }^{* *} p<0.01$ 
Table 1 showed burden of caregiving according to socio-demographic variables. The mean score on caregiving burden was found to be high among caregivers belonging to age group 60-65 years $(82.00 \pm 10.229)$, widow $(84.00 \pm 3.606)$, with education up to master level (85.20 \pm 17.936), having employment $(80.39 \pm 13.236)$ and from upper middle socio-economic status (77.60 \pm 20.452). Likewise, the mean score on caregiving burden was high among the caregivers following Christianity $(76.33 \pm 11.59)$, from urban areas (75.25 \pm 13 . 914), from nuclear family (75.75 \pm 12.432$)$, with family history of mental illness $(73.14 \pm 12.944$. One way ANOVA showed no significant difference in the distribution of burden by age, educational level, occupation, socioeconomic status and religion. Highly significant difference was found in the distribution of burden by marital status ( $F=5.15$, $\mathrm{df}=2, \mathrm{p}<0.01$ ). The $\mathrm{t}$-test showed no significant difference in the distribution of burden by family type, permanent residence and family history of mental illness.

Table 2 illustrated the distribution of experience of burden of caregiving to people with mental illness according to different illness variables. Mean score burden was found to be high among caregivers of patients with more than five years of illness (75.45 \pm 14.007$)$, with mood disorders (79.12 \pm 10.176$)$, with first hospitalization (75.96 $\pm 12.833)$ and cared by spouse (82.67 \pm 9.642$)$.

One way ANOVA showed no significant difference in the distribution of burden by total duration of illness, type of illness and number of hospitalization where as highly significant difference was found in the distribution of burden according to caregiver's relation with the patient $(\mathrm{F}=7.493, \mathrm{df}=3, p<0.01)$.

Table 2: Illness Variables and Caregiving Burden (N=56)

\begin{tabular}{|c|c|c|c|c|c|c|}
\hline Illness Variables & $\mathbf{N}$ & Mean & SD & F-ratio & dff & p value \\
\hline Total Duration of Illness & & & & & & \\
\hline Less than one year & 10 & 70.90 & 13.609 & \multirow{4}{*}{.425} & \multirow{4}{*}{2} & \multirow{4}{*}{$\begin{array}{l}.656 \\
\text { (NS) }\end{array}$} \\
\hline $1-5$ year & 17 & 74.88 & 12.995 & & & \\
\hline More than 5 years & 29 & 75.45 & 14.007 & & & \\
\hline Total & 56 & 74.46 & 13.497 & & & \\
\hline \multicolumn{7}{|l|}{ Type of Illness } \\
\hline Schizophrenia and Psychotic Disorders & 26 & 77.00 & 13.711 & \multirow{6}{*}{1.227} & \multirow{6}{*}{4} & \multirow{6}{*}{$\begin{array}{l}.311 \\
\text { (NS) }\end{array}$} \\
\hline Mood Disorders & 8 & 79.12 & 10.176 & & & \\
\hline Neurotic and Stress Related Disorders & 11 & 71.00 & 10.936 & & & \\
\hline Childhood Disorders & 2 & 71.50 & 30.406 & & & \\
\hline Substance Related Disorders & 9 & 67.89 & 14.120 & & & \\
\hline Total & 56 & 74.46 & 13.497 & & & \\
\hline \multicolumn{7}{|l|}{ No of Hospitalization } \\
\hline First & 23 & 75.96 & 12.833 & \multirow{4}{*}{.244} & \multirow{4}{*}{2} & \multirow{4}{*}{$\begin{array}{l}.789 \\
\text { (NS) }\end{array}$} \\
\hline Second & 14 & 73.00 & 15.044 & & & \\
\hline Third or More & 19 & 73.74 & 13.670 & & & \\
\hline Total & 56 & 74.46 & 13.497 & & & \\
\hline \multicolumn{7}{|l|}{ Caregiver's Relation with Patient } \\
\hline Parents (Father/Mother) & 24 & 78.38 & 12.60 & \multirow{5}{*}{7.493} & \multirow{5}{*}{3} & \multirow{5}{*}{$.000^{* *}$} \\
\hline Spouse & 12 & 82.67 & 9.642 & & & \\
\hline Children (Son/Daughter) & 9 & 65.11 & 11.252 & & & \\
\hline Sibling & 11 & 64.64 & 11.439 & & & \\
\hline Total & 56 & 74.46 & 13.497 & & & \\
\hline
\end{tabular}

Note: NS $=$ Not significant, ${ }^{* *} p<0.01$ 
Table 3: Level of Burden on Burden Assessment Schedule (BAS) $(\mathrm{N}=56)$

\begin{tabular}{|c|c|c|c|c|}
\hline $\begin{array}{l}\text { Level of } \\
\text { Caregiving } \\
\text { Burden }\end{array}$ & $\begin{array}{l}\text { BAS } \\
\text { Range }\end{array}$ & N (\%) & $\begin{array}{l}\text { Mean } \\
\text { (SD) }\end{array}$ & p value \\
\hline Minimal & $40-60$ & $10(17.9)$ & $\begin{array}{l}54.50 \\
(4.503)\end{array}$ & \multirow{4}{*}{$\begin{array}{l}\mathrm{F}=81.57 \\
\mathrm{df}=3, \\
\mathrm{p}=.000 * *\end{array}$} \\
\hline Moderate & $61-80$ & $27(48.2)$ & $\begin{array}{l}71.78 \\
(6.559)\end{array}$ & \\
\hline Severe & $81-100$ & $18(32.1)$ & $\begin{array}{l}88.06 \\
(5.173)\end{array}$ & \\
\hline $\begin{array}{l}\text { Very } \\
\text { Severe }\end{array}$ & $\begin{array}{l}101- \\
120\end{array}$ & $1(1.8)$ & 102.00 & \\
\hline Total (N) & $40-120$ & $56(100)$ & $\begin{array}{l}74.46 \\
13.497)\end{array}$ & \\
\hline
\end{tabular}

Note: ${ }^{* *} p<0.01$

Table 3 shows the levels of caregiving burden. $48.2 \%$ of caregivers had moderate level of caregiving burden (Mean \pm SD:71.78 \pm 6.56 ) and $32.1 \%$ had severe level of burden (Mean \pm SD:88.06 \pm 5.173). Highly significant difference was observed in the distribution of burden according to severity $(\mathrm{F}=81.57, \mathrm{df}=3$, $\mathrm{p}<0.01)$.

Table 4: Distribution of Level of Caregiving Burden on BAS according to Caregivers' Sex $(\mathrm{N}=56)$

\begin{tabular}{|c|c|c|c|c|}
\hline $\begin{array}{l}\text { Level of } \\
\text { Caregiving } \\
\text { Burden }\end{array}$ & $\begin{array}{l}\text { Male } \\
\text { n (\%) }\end{array}$ & $\begin{array}{l}\text { Female } \\
\text { n (\%) }\end{array}$ & $\begin{array}{l}\text { Total N } \\
(\%)\end{array}$ & p value \\
\hline Minimal & $\begin{array}{l}5 \\
(8.9)\end{array}$ & $\begin{array}{l}5 \\
(8.9)\end{array}$ & $\begin{array}{l}10 \\
(17.9)\end{array}$ & \multirow{4}{*}{$\begin{array}{l}x^{2}=1.26 \\
d f=3, \\
p=.739 \\
\text { (NS) }\end{array}$} \\
\hline Moderate & $\begin{array}{l}13 \\
(23.2)\end{array}$ & $\begin{array}{l}14 \\
(25.0)\end{array}$ & $\begin{array}{l}27 \\
(48.2)\end{array}$ & \\
\hline Severe & $\begin{array}{l}10 \\
(17.9)\end{array}$ & $\begin{array}{l}8 \\
(14.3)\end{array}$ & $\begin{array}{l}18 \\
(32.1) \\
\end{array}$ & \\
\hline $\begin{array}{l}\text { Very } \\
\text { Severe }\end{array}$ & - & $\begin{array}{l}1 \\
(1.8)\end{array}$ & $\begin{array}{l}1 \\
(1.8)\end{array}$ & \\
\hline Total (N) & $\begin{array}{c}28 \\
(50)\end{array}$ & $\begin{array}{c}28 \\
(50)\end{array}$ & $\begin{array}{l}56 \\
(100)\end{array}$ & \\
\hline
\end{tabular}

Note: NS $=$ Not Significant

Table 4 showed that $8.9 \%$ of both male and female caregivers reported minimal level of burden; $23.2 \%$ of male and $25.0 \%$ female caregivers reported moderate level of burden; $17.9 \%$ of male and $14.3 \%$ of female caregivers reported severe level of burden; and only $1.8 \%$ of female caregiver reported very severe level of burden. No significant difference was observed in the distribution of burden level among caregivers according to $\operatorname{sex}\left(x^{2}=1.26, \mathrm{df}=3, p\right.$ $>.05)$.

\section{DISCUSSION:}

Majority of family caregivers in the present study reported moderate to severe level of caregiving burden. Though no significant difference was observed in the distribution of caregiving burden in total and in different domains of BAS on the basis of sex, as the task of caregiving has been shouldered by female in different context throughout the world, most caregivers in studies reviewed in literature showed female to be the main caretakers in different physical and mental illnesses. The sex wise distribution of burden in different dimensions of Burden Assessment Schedule showed that female caregivers reported more spouse related burden than that of male. As female caretakers were mostly spouses of patients with alcohol related disorders and that might have increased the extent of burden. In a review of recent studies on alcohol ${ }^{13}$ found that the alcoholic's family distinguishes itself from other families in that there may be a negative, critical, hostile, and rejectionist environment which is eventually passed on to their own children. A person with long term alcohol use show poor adjustment in their relationships with his wife and children, and there is expression of dissatisfaction and disinterest in dyadic relationship which increases their vulnerabilities to some other co-morbid psychiatric conditions like anxiety, depression etc.

Though no significant difference was observed in the distribution of burden by total duration of illness, type of illness and number of hospitalization, other studies have found significant difference in these variables (REF). In the present study, significant difference was found in the distribution of burden according to caregiver's relation with the patient $(\mathrm{F}=7.493$, $\mathrm{df}=3, p=.000<0.05)$. Caregivers experience burden in different dimensions and its extent depends on various characteristics of both 
caregivers and patients. Employed caregivers reported higher level of burden of caregiving than unemployed and self employment caregivers. Higher level of burden was found among upper middle socio-economic status caregivers. Burden was found high among the married. As being married changes the role and increases responsibilities, the differential experience of burden is apparently understood. Majority of the patients in the present study were admitted for the first time (41.1\%) followed by $33.9 \%$ for the third or more hospitalization and with total duration of illness more than 5 years $(51.8 \%)$. These two factors have found to be significant in increasing the experiences of burden among the caregivers, especially in first episode psychotic and mood disorders. The psychotic symptoms occurring for the first time are more frightening for the spouse of the person affected as the illnesses occur unexpectedly. In this situation, feelings of powerlessness, fear, and despair are often overwhelming $^{13}$. The reported moderate to severe level of burden among the study caregivers supports the earlier findings. Parents of schizophrenia patients having problems and worries regarding the parent-child relation are of importance, such as the question of possibly being responsible for the illness because of poor parenting, and the dilemma of a permanent, possibly lifelong dependency of the patient ${ }^{15}$. Family intimacy and conflict have been found to reflect the degree of burden or reward experienced and it is suggested that the family system, as the context within which the patient exists, is seen as the mediating environment for caregiving burden and reward ${ }^{16}$.

Stigma attached to mental illness complicates care-giving for the family as it may lead to the increased social isolation of the affected family or the individual care-giver, financial difficulties, restrictions on the educational or occupational advancement of family members or the care-giver in particular, increased anxiety and feelings of helplessness, reduction in leisure time activities and breakdowns in social relationships ${ }^{17}$. Along with stigma experience itself, the amount of care-giver strain experienced and the degree to which the patient is dependent on the care-giver all represent major problems for the resilience of care-givers ${ }^{18}$, 19.

\section{CONCLUSION:}

The study concluded that family caregivers of people with mental illness experience significant levels of caregiving burden and is associated with different socio-demographic characteristics of both patients and caregivers. In the country like Nepal where there are very few mental health professionals and stigma associated with mental illness are widely prevalent which maintains the people's hesitation to seek mental health treatment in the community, caregivers' self-help organization can be established to make integrated actions to reduce caregiving burden, learn better coping strategies and strengthen social support system. These initiatives can be helpful to plan and implement preventive measures and to ensure better treatment and rehabilitation facilities.

\section{REFERENCES:}

1. Sartorius, N., Leff, J., Jos'e L'opez-Ibor, J., Maj, M. and Okasha, A. (Eds) (2005). Families and Mental Disorders: From Burden to Empowerment. John Wiley \& Sons Ltd.

2. World Health Organization (2001). The World Health Report 2001: Mental Health - New Understanding, New Hope. WHO, Geneva.

3. Pai, S. and Kapur, R. L. (1982). Impact on treatment intervention on the relationship between the dimensions of clinical psychopathology, social dysfunction and burden on families of schizophrenic patients. Psychological Medicine, 12: 651-658.

4. Fadden, G., Bebbington P. and Kuipers, L. (1987). The burden of care: the impact of functional psychiatric illness on the patient's family. British Journal of Psychiatry, 150:285292.

5. Winefield H.R. and Harvey, E.J. (1994). Needs of family care-givers in chronic schizophrenia. Schizophrenia Bulletin, 20(3): 557-566.

6. Murray, C. J. and Lopez, A. D, (1996). The global burden of disease: a comprehensive assessment of mortality and disability from diseases, injuries and risk factors in 1990 and projected to 2020. Cambridge, MA, Harvard School of Public Health on behalf of the World Health Organization and the World Bank (Global Burden of Disease and Injury Series, Vol. I). 
7. Chien, W. T., Chan, S., and Morrissey, J. (2007). The perceived burden among Chinese family caregivers of people with schizophrenia. Journal of Clinical Nursing, 16, 1151-1161.

8. Gandhi, S. and Tennarasu, K. (2012). Burden among Caregivers of Clients with Depression- A Scientific Study, International Journal of Advanced Nursing Science and Practice, 1(1):20-28.

9. Zahid, S. and Ohaeri, R. (2010). Relationship of family caregiver burden with quality of care and psychopathology in a sample of Arab subjects with schizophrenia. BMC Psychiatry, 10:71

10. Thara, R., Padmavathi, R., Kumar, S. and Srinivasan, L. (1998) Burden assessment schedule: instrument to assess burden on caregivers of chronic mentally ill. Indian Journal of Psychiatry, 40, 21-29

11. Pai, S. \& Kapur, R.L. (1981). The burden of the family of a psychiatric patient: development of an interview schedule. British Journal of Psychiatry, 138, 331-335.

12. Swapna B, Sudarshan DY and Shamshad Begum (2012).Burden on caregivers in Bipolar Affective Disorder and Alcohol, Int J Biol Med Res. 2012; 3 (3): 1992-1997

13. Kaur, D. and Ajinkya, S. (2014). Psychological impact of adult alcoholism on spouses and children. Med J DY Patil Univ; 7:124-7.

14. Jungbauer J, Wittmund B, Dietrich S, Angermeyer MC (2004). The disregarded caregivers: Spouses of schizophrenic patients and their living situation. Schizophrenia Bulletin, 30:665-675.

15. Jungbauer, J., and Angermeyer, M.C. (2002). Living with a schizophrenic patient: A comparative study of burden as it affects parents and spouses. Psychiatry, 65:110-123.

16. Heru, A. and Rayan, C. (2008). Burden, reward and family functioning of caregivers for relatives with mood disorders: 1 year follow up. Journal of Affective Disorders, 83 (23); 221-225.

17. Muhlbauer, S. (2002). Experiences of stigma by families with mentally ill members. Journal of the American Psychiatric Nurses Association 8: 76-83.

18. Zauszniewski, J., Bekhet, A. and Suresky, M. (2009). Effects on resilience of women family caregivers of adults with serious mental illness: the role of positive cognitions. Archives of Psychiatric Nursing 23(6): 412 422.
19. Swaroop, R. (2013) Burden among Caregivers of Mentally- Ill Patients: A Rural Community - Based Study Int. J Res Dev Health, 1(2). 